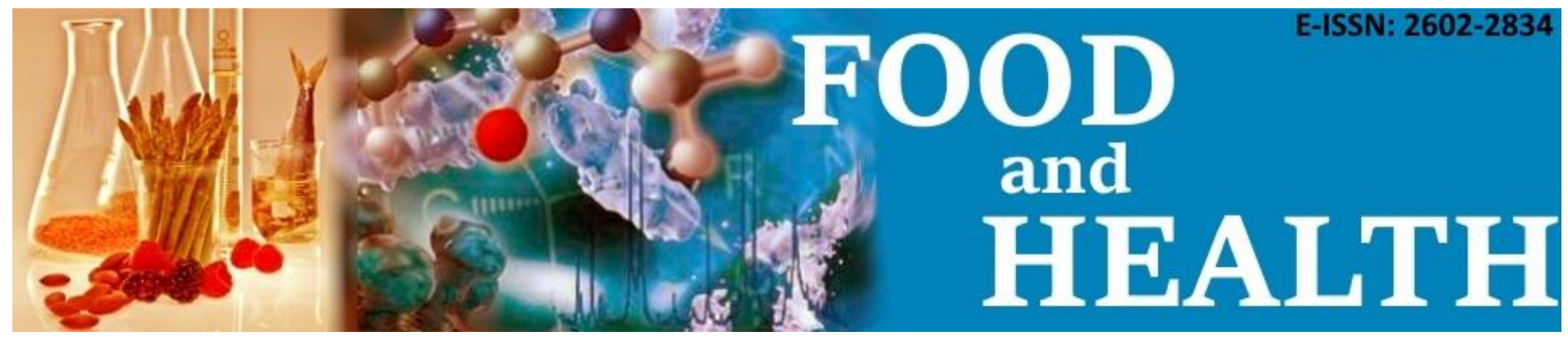

\title{
FT-IR SPECTROSCOPY CHARACTERIZATION AND CHEMOMETRIC EVALUATION OF LEGUMES EXTRACTED WITH DIFFERENT SOLVENTS
}

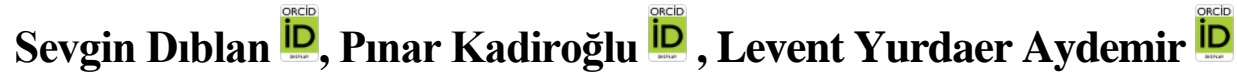

Cite this article as:

Diblan, S. Kadiroğlu, P., Aydemir, L.Y. (2018). FT-IR spectroscopy characterization and chemometric evaluation of legumes extracted with different solvents. Food and Health, 4(2), 80-88. DOI: 10.3153/FH18008

Adana Science and Technology University, Faculty of Engineering, Department of Food Engineering, Adana, Turkey

Submitted: 25.04 .2017

Accepted: 07.10.2017

Published online: 14.01.2018

Correspondence:

\section{Pınar KADİROĞLU}

E-mail: pkadiroglu@adanabtu.edu.tr

๑Copyright 2018 by ScientificWebJournals

Available online at

www.scientificwebjournals.com

\begin{abstract}
In this study, FT-IR spectroscopy was applied for rapid characterization and discrimination of commonly consumed legumes extracted by different solvents in combination with principal component analysis (PCA) for the first time. Dried soy bean, white bean, chickpea, red lentil, and pinto bean were extracted by water (W), ethanol (E), acetone/water (AW) and acetone/water/acetic acid (AA). The effect of each solvent on different legume extracts was demonstrated by identifying the functional groups using FT-IR spectroscopy at mid-infrared (mid-IR) range $\left(4000-650 \mathrm{~cm}^{-1}\right)$ and associated with the amount of total phenolics and other oxidation substrates in the extracts determined by Folin-Ciocalteu method. PCA models with 2 principal components were constructed to discriminate the different legume extracts based on FT-IR spectra and total phenolic content (TPC). FT-IR spectra of each legume were quite different for different solvents but almost the same for the same solvent. Each legume extracts had significantly different TPC from each other extracted with the same or different solvents. The highest TPC was obtained by soybeans and pinto beans extracted with W or E and AW or AA, respectively. PCA analysis of FT-IR spectra and TPC provided clear discrimination between the legume samples extracted with different solvents.
\end{abstract}

Keywords: Infrared spectroscopy, Legumes, Functional groups, PCA 


\section{Introduction}

Legumes are important sources of proteins, carbohydrates, vitamins and minerals, constituting the significant part of human diet. They are also good complement for cereal based foods which are low in essential amino acids and phenolic compounds. However, legumes may exert protective effects on human health by showing antioxidant and anticancerogenic activities. According to the studies, legumes may prevent and control metabolic diseases, diabetes mellitus, colon cancer, and cardiovascular diseases by providing anti-microbial, cardioprotective, anti-allergenics and anti-inflammatory activities (Chung \& Liu, 2012; Hurtado-Fernández, Gómez-Romero, Carrasco-Pancorbo, \& FernándezGutiérrez Alberto, 2010; Koehnlein et al., 2016; Zhao, Du, Wang, \& Cai, 2014). In food production, phenolic compounds extracted from legumes can be used as antioxidant additives in the formulas to prevent oxidation of lipids and provide health promotion (Escarpa \& Gonzalez, 2001). To use phenolic compounds in food formulations is challenging in some cases due to different solubility properties of these compounds. According to the studies water and alcohol were the most used solvents to extract phenolic compounds from legumes followed by acetone and acidified acetone (Koehnlein et al., 2016; B. J. Xu \& Chang, 2007).

Infrared spectroscopy which is based on the interaction of molecules or atoms with electromagnetic radiation, works by passing a beam of IR radiation through a sample and comparison of the radiation transmitted through the sample with that transmitted without the sample. Fourier transform infrared spectroscopy (FT-IR) is a simple, rapid and nondestructive vibrational spectroscopic method that provides molecular specific information for the complicated mixture system (Graham Solomon, Craig Fryhle, 2014). Multivariate statistical analysis methods such as principal component analysis (PCA) could be used to generate information from FT-IR data. PCA is an unsupervised discrimination method generating principal components explaining variability in the data set (Eriksson et al., 2001). Studies on FT-IR spectroscopic analyses were performed on discrimination of edible oils (Javidnia, Parish, Karimi, \& Hemmateenejad, 2013), prediction of geographical origins of butters (Bassbasi, De Luca, Ioele, Oussama, \& Ragno, 2014), classification of tea varieties (Cai, Wang, Xi, Li, \& Wei, 2015), detection of authentication and adulteration purposes (Gurdeniz \& Ozen, 2009; Li, Wang, Zhao, Ouyang, \& Wu, 2015; Rohman, Riyanto, Sasi, \& Yusof, 2014; L. Xu, Cai, Cui, Ye, \& Yu, 2012) and for differentiation of pea and oat roots (Naumann, Heine, \& Rauber, 2010). FT-IR analyses have also potential to be applied to other food commodities to determine their functional groups found in their different extracts also to discriminate the effects of different solvents on these functional groups.

The aim of this study is to characterize different legumes extracted by different solvents for the first time using their FT-IR spectra and to differentiate the legume extracts depending on their functional groups with PCA method in correlation with their total phenolic contents.

\section{Materials and Methods}

\section{Chemicals and Reagents}

Folin Ciocalteu reagent, gallic acid, and sodium carbonate were purchased from Merck (Darmstadt, Germany). All solvents and chemicals used for analyses were analytical grade.

\section{Legume Samples}

Five legume samples that were red lentil (RL), dry (white) bean (DB), pinto bean (PB), chickpea (CP) and soy bean (SB) were purchased from local market in Adana, Turkey. Moisture content of the legumes was determined by drying the sample in an oven at $105^{\circ} \mathrm{C}$ until a constant weight was obtained (AOAC 2000). TPC of different extracts were expressed on dry weight basis.

\section{Extraction of Legume Samples}

The legume samples were grounded with IKA grinder (IKA Works Inc., Wilmington, N.C., U.S.A.). $1 \mathrm{~g}$ of legumes powder was extracted in $10 \mathrm{~mL}$ of extraction solvent (water, ethanol, acetone/water $(50: 50, \mathrm{v} / \mathrm{v})$ or acetone/water/acetic acid $(70: 29.5: 0.5, \mathrm{v} / \mathrm{v} / \mathrm{v})$ on an orbital shaker (IKA) (300 $\left.\mathrm{rpm}, 25^{\circ} \mathrm{C}, 3 \mathrm{~h}\right)$. The extracts were centrifuged at $3000 \mathrm{rpm}$ for $10 \mathrm{~min}$ at $4^{\circ} \mathrm{C}$ and supernatants were removed (Hettich, Universal $320 \mathrm{R}$, Germany) and analyzed immediately without any delay. Extractions were performed in 3 replicates for all legume-solvent extraction mixture.

\section{Determination of Total Phenolic Content}

Total phenolic content (TPC) of the extracts was determined by a Folin Ciocalteu assay (Singleton \& Rossi, 1965) using gallic acid (GA) as the standard. Firstly, $200 \mu \mathrm{L}$ of the legume extract and $1000 \mu \mathrm{L}$ of Folin-Ciocalteu's (10-fold diluted in distilled water) reagents solution were mixed and reacted for $3 \mathrm{~min}$ and then $800 \mu \mathrm{L}$ of $7.5 \% \mathrm{NaCO}_{3}(\mathrm{w} / \mathrm{v})$ was added into the solution and further incubated for 2 hours at room temperature in the dark. The absorbance of the solutions was measured at $765 \mathrm{~nm}$ and TPC results were expressed as gallic acid equivalents ( $\mu \mathrm{g}$ of GAE/g dry seed). 


\section{Fourier Transform Infrared (FT-IR) Spectroscopic Analysis}

FT-IR spectroscopy was used to characterize the functional groups in the legume extracts. The IR spectrum was obtained by using PerkinElmer Spectrum Two (Perkin Elmer Inc., USA). One drop of each extract was added onto absorbance chamber and the samples were scanned at mid-infrared range from $4000 \mathrm{~cm}^{-1}$ to $450 \mathrm{~cm}^{-1}$ in triplicate.

\section{Statistical Analysis}

Statistical analysis was performed using Minitab17 (Minitab Inc., State College, USA) software. Analysis of variance (ANOVA) analysis method was applied to demonstrate the significance of differences among the samples at $P<0.05$ level. PCA analysis was performed by using the spectral ranges of 3750-2750 and $1800-750 \mathrm{~cm}^{-1}$.

\section{Results and Discussion}

\section{FT-IR Characterization of Legume Extracts}

FT-IR spectroscopy was applied for evaluation of different legume extracts obtained by four different solvents namely water (W), ethanol (E), acetone/water (AW), and acidified acetone/water (AA) in the mid-IR range and given in Figure 1. When the graphs were investigated, it was seen that all legumes gave mostly similar spectra for the same solvent type while completely different spectra for different solvent type. As can be examined, along with small differences between solvents, the bands between wavenumbers 3730$830 \mathrm{~cm}^{-1}$ revealed the presence of various phytochemical compounds extracted with different solvents. The major bands in mid-IR range showed that all legume extracts may have distinct compounds such as alcohol, amides, amines, fluoride, iodide, chloride, phosphine, bromide, sulfonates, aliphatic organo halogens, aliphatic and aromatic nitro compounds (Marimuthu \& Gurumoorthi, 2013).

All different solvent extractions have led to various bands from high to low wavenumbers; similar with total polyphenol content results which pointed out the significance of solvent type on extraction of bioactive compounds from legumes. As shown in Figure 1, although peaks of DBW were much larger whereas others were downstream or flat, all samples gave similar spectra for water extraction as well as other solvent extractions. The bands between 3730 and 3361 $\mathrm{cm}^{-1}$ reflected $\mathrm{O}-\mathrm{H}$ and $\mathrm{N}-\mathrm{H}$ stretching for alcohol especially in legumes extraction with ethanol, acetone and acidified acetone. This band also characterizes amines that are found in amino acids, peptides, proteins, alkaloids, DNA and RNA because of amino $\left(\mathrm{NH}_{2}\right)$ groups (Marimuthu \& Gurumoorthi, 2013). The spectrum of water soluble extract of dry bean was the most different one from other extracts.
It gave two negative peaks between 3600 and $3000 \mathrm{~cm}^{-1}$ and 1800 and $1500 \mathrm{~cm}^{-1}$ which were identical with the spectra of ethanol and acetone solvent extracts of dry beans. These showed that the dry bean had the functional groups which were soluble in both water and organic solvents. Bands in the region between $1800-900 \mathrm{~cm}^{-1}$ are mainly attributed to fingerprints region for typical absorption of phenolic molecules such as the stretching band of carbonyl $(\mathrm{C}=\mathrm{O})$ groups $\left(1712-1704 \mathrm{~cm}^{-1}\right)$. Especially in the spectra of acetone and acidified acetone extraction of legumes, the peaks of 1702$1704 \mathrm{~cm}^{-1}$ were very high. Also, bands in the $1680-900 \mathrm{~cm}^{-}$ ${ }^{1}$ region correspond to phenols. The bands between 1448$1444 \mathrm{~cm}^{-1}$ are due to the asymmetric in-plane bending of $\mathrm{CH}_{3}$ (Silva, Feliciano, Boas, \& Bronze, 2014) which is also the same spectral region reflecting to the phenyl nuclei $(\mathrm{C}=\mathrm{C}$ bonds $)$ in ethanol extracts of legumes. The biochemical compositions, especially carbohydrate, lipid, protein structures and polyphenols give absorption bands in the 1800 to $900 \mathrm{~cm}^{-1}$ region (Silva et al., 2014). As shown in Table 1, according to the solvent extraction methods, the spectra collected by FT-IR were differed from each other. For example, the $1295-1232 \mathrm{~cm}^{-1}$ region corresponding to O-C-H bending of phenolic compounds ( $\mathrm{Lu}$ et al., 2011; Singh et al., 2016) were obtained from all extracts except water extracts of red lentil and dry bean. It was noteworthy that the region between 1563 and $1551 \mathrm{~cm}^{-1}$ which was corresponding to amide II C-N and N-H stretching of proteins were found in water extracts of legumes. The absorption bands that were attributed to C-C stretching vibration of phenyl at $1657-1632 \mathrm{~cm}^{-1}$ region were observed in all legume extracts. However, the bands at $891-830 \mathrm{~cm}^{-1}$ indicated C-C-O in plane stretching of primary and secondary alcohols and $\mathrm{CH}$ deformation (polyphenols) and the band at $1338 \mathrm{~cm}^{-1}$ referred to C-O stretching vibration of phenyl obtained from legumes extracted with ethanol mainly (LinVien et al., 1991; Lu et al., 2011; Silva et al., 2014). In the study reported by Marimuthu \& Gurumoorthi (2013), phytochemical and FT-IR spectroscopic analysis was performed to determine the chemical constituents and to identify the functional groups in velvet bean, horse gram, lima bean and jack bean. FT-IR analysis results revealed the presence of alcohol and hydroxyl groups, alkane groups, alkenes groups, nitrogen-oxy groups, sulfuroxy groups, aryl groups, aliphatic iodo groups in wild and common legumes. 
Table 1. Functional groups and modes of vibrations of legume extracts

\begin{tabular}{|c|c|c|}
\hline Frequency $\left(\mathrm{cm}^{-1}\right)$ & Functional group assignment & References \\
\hline $3712-2839$ & Hydroxyl compounds & (Hu et al., 2016; Silva et al., 2014) \\
\hline 2938 & $\mathrm{CH}_{2}$ from lipids & (Lu et al., 2011) \\
\hline $2341-2337$ & $\mathrm{CO}_{2}$ group & (Sanati \& Andersson, 1993) \\
\hline $1704-1702$ & Carbonyl groups; $\mathrm{C}=\mathrm{O}$ bonds for lipids & (Silva et al., 2014; Lu et al., 2011) \\
\hline $1657-1632$ & $\mathrm{C}=\mathrm{C}$ stretching of phenyl & (Silva et al., 2014) \\
\hline $1657-1632$ & $\begin{array}{l}\text { Amide } \mathrm{I}(\mathrm{C}=\mathrm{O} \text { stretching }) \text { : proteins and peptides, } \\
\text { native protein }\end{array}$ & (Demir et al., 2015; Guerrero et al., 2014) \\
\hline $1563-1551$ & Amide II (C-N and N-H stretching): proteins & (Demir et al., 2015; Naumann et al., 2010) \\
\hline $1551-1460$ & N-H bonds, proteins & (Guerrero et al., 2014) \\
\hline $1429-1411$ & $\mathrm{C}-\mathrm{H}$ and $\mathrm{O}-\mathrm{H}$ bending, $-\mathrm{CH}_{3}$ & (Silva et al., 2014; Singh et al., 2016) \\
\hline $1385-1367$ & Cellulose, phosphine, sulfate groups & $\begin{array}{l}\text { (Demir et al., 2015; Guerrero et al., 2013; } \\
\text { Marimuthu \& Gurumoorthi, 2013; Naumann } \\
\text { et al., 2010) }\end{array}$ \\
\hline 1338 & $\mathrm{C}-\mathrm{O}$ stretching (phenyl), $\mathrm{C}-\mathrm{H}$ bending and $\mathrm{CH}_{2}$ & (Lu et al., 2011; Silva et al., 2014) \\
\hline $1295-1232$ & $\begin{array}{l}\mathrm{O}-\mathrm{C}-\mathrm{H} \text { bending (phenolic), } \mathrm{O}-\mathrm{H} \text { in-plane, Amide } \\
\text { III proteins, sulphates }\end{array}$ & (Lu et al., 2011; Singh et al., 2016) \\
\hline $1099-1074$ & $\begin{array}{l}\text { Carbohydrate (Starch, pectin), C-O stretching (es- } \\
\text { ter), ester sulfates rings }\end{array}$ & (Guerrero et al., 2013; Singh et al., 2016) \\
\hline 1046 & $\begin{array}{l}\text { Flurides, }-\mathrm{CH}_{2} \mathrm{OH} \text { (carbohydrate), }-\mathrm{CH}_{3} \text { (poly- } \\
\text { saccharide) }\end{array}$ & (Lu et al., 2011) \\
\hline $928-911$ & Starch & (Demir et al., 2015) \\
\hline $891-881$ & $\begin{array}{l}\mathrm{C}-\mathrm{C}-\mathrm{O} \text { in phase stretching of primary and secon- } \\
\text { dary alcohols }\end{array}$ & (Lin-Vien et al., 1991) \\
\hline 830 & C-H deformation (polyphenols) & (Lu et al., 2011) \\
\hline
\end{tabular}

PCA analysis was performed to aim at interpreting the FTIR results for discrimination of legume samples according to the solvent types. PCA model was constructed with 2 principal components account for $98.1 \%$ of total variance. PC1 explained $78.6 \%$ of the variance and PC2 explained $19.5 \%$ of total variance. PCA score plot for the first two principal components of legume extracts' FT-IR spectra was shown in Fig. 2a. Samples were discriminated clearly according to solvent types. A few numbers of studies were performed on FT-IR analysis of legume extracts. In one of these studies, different kidney bean and field pea line protein isolates were investigated to determine their functional properties by FT-IR method in relation with PCA and it was reported that $\beta$-sheets, $\beta$-turns and $\alpha$-helix were the major secondary structures in kidney bean and field pea line (Shevkani, Singh, Kaur, \& Rana, 2015).
Total Phenolic Compounds of Legumes Extracted By Different Solvents

Although detailed chromatographic characterization methods are being applied to determine the phenolic content of plant samples, Folin-Ciocalteu $(\mathrm{F}-\mathrm{C})$ method still has been proposed as a standardized method for determination of total phenolic content of food products. Despite the method allows some interactions with the results of phenolic contents, it is still a point of origin for detailed characterizations especially when the subject is antioxidant potential. FolinCiocalteu method measures the phenolic acids also with soluble proteins and carbohydrates which are readily oxidizable under test conditions in the sample. In literature, TPC of different legumes were determined using different solvents, pretreatments, or equivalents which reports different results causing the inconsistency. Thus, there was a need for comparison of TPCs obtained from different extraction sys- 
tems applied to different legume types. According to the measurements, TPC of different legume samples varied from 1704 to $3095 \mu \mathrm{g} \mathrm{GA} / \mathrm{g}$, from 560 to $2973 \mu \mathrm{g} \mathrm{GA} / \mathrm{g}$, from 875 to $1692 \mu \mathrm{g} \mathrm{GA} / \mathrm{g}$, and from 535 to $6055 \mu \mathrm{g} \mathrm{GA} / \mathrm{g}$ in their water soluble, ethanol soluble, acetone/water soluble, and acidified acetone/water soluble extracts, respectively (Table 2). Soybean had the highest TPC values in its $\mathrm{W}$ and E extracts, while pinto bean had the highest TPC in its AW and AA extracts. The significant differences were determined between TPC values of different solvent extracts of each legume $(P<0.05)$. The similar significant differences were also demonstrated between the TPC values of different legumes extracted with the same solvent. TPCs of ethanol soluble extracts of each legume were significantly lower than those of water soluble extracts indicating that water soluble proteins also contributed to the TPC. This situation was clearly seen in FT-IR spectra obtained for legumes extracted with water and ethanol. FT-IR spectrum of water extracts of legumes had the $\mathrm{C}=\mathrm{O}$ stretching amide $\mathrm{I}, \mathrm{N}-\mathrm{H}$ bending and $\mathrm{C}-\mathrm{N}$ stretching amide II, and $\mathrm{N}-\mathrm{H}$ bending and $\mathrm{C}-\mathrm{H}$ stretching amide III bands belonging to proteins while these bands were absent in the FT-IR spectrum of ethanol extracts of legumes. In plants, total phenolic compounds were mainly evaluated by summation of water soluble and alcohol soluble extracts of sample. In this respect, soybean had the highest total phenolic content followed by in order of pinto bean, chickpea, red lentil and dry bean. Acetone extractions of legume samples contained both acetone and water soluble fragments of legumes and acidification of this solvent significantly increased or decreased the total phenolic content of legume extracts $(P<0.05)$. The similar extraction methods were applied by $\mathrm{Xu}$ and Chang (2007) who compared the total phenolic content, total flavonoid content and condensed tannin content in different legume extracts by different solvent systems. The TPCs of soybean extracts obtained by AW and AA were comparable however total phenolic content of ethanolic extracts of chickpea and yellow soybean could not be determined. TPCs of acetone and acidified acetone extracts of chickpea and lentil were almost 2 and 5 fold higher than those obtained in this study. Similar to our findings, Oomah et al. (2011) determined the highest TPC in red lentils extracted with water followed by acetone and ethanol solvents. Koehnlein et al. (2016) found significant but low positive correlation between TPC and antioxidant activities of different legume extracts obtained by water as a solvent. For this reason, the legume samples could be used as antioxidant additive in functional foods after suitable solvent extractions compatible with the process of food product. Strong and positive correlation was also determined between the acetone extracts and acidified acetone extracts of legumes with Pearson correlation coefficient (r) of 0.937 while positive correlations were observed between water extracts and ethanol extracts $(\mathrm{r}=0.703)$ and acidified acetone extracts $(\mathrm{r}=0.748)$ (Data not shown) $(P<0.05)$. PCA score plots for the first two principal components of legume extracts' FT-IR spectra and total phenolic contents according to legume type and solvent system were given in Fig. $2 \mathrm{~b}$ and $2 \mathrm{c}$. PCA models according to legume types were constructed with 2 principal components account for $92 \%$ of total variance. PC1 explained $82 \%$ of the variance and PC2 explained $10 \%$ of total variance. PCA models according to solvent types were constructed with 2 principal components account for $99 \%$ of total variance. PC1 explained $88 \%$ of the variance and PC2 explained $11 \%$ of total variance. PCA score plots demonstrated the clear discrimination among the samples according to legume types and solvent systems in correlation with FT-IR data.

Table 2. Total phenolic content of legume samples extracted with different solvents ( $\mu \mathrm{g} \mathrm{GA} / \mathrm{g}$ dry legume)

\begin{tabular}{cccccc}
\hline & Red lentil & Dry bean & Pinto bean & Chickpea & Soybean \\
& & & & & \\
\hline Water extraction & $2254 \pm 31^{\mathrm{aC} *}$ & $1704 \pm 19^{\mathrm{aE}}$ & $2721 \pm 21^{\mathrm{cB}}$ & $1829 \pm 12^{\mathrm{aD}}$ & $3095 \pm 21^{\mathrm{aA}}$ \\
Ethanol extraction & $853 \pm 12^{\mathrm{dCD}}$ & $560 \pm 42^{\mathrm{cD}}$ & $1319 \pm 4^{\mathrm{dBC}}$ & $1478 \pm 79^{\mathrm{bB}}$ & $2973 \pm 21^{\mathrm{bA}}$ \\
Acetone extraction & $1307 \pm 23^{\mathrm{cD}}$ & $1384 \pm 12^{\mathrm{bC}}$ & $5465 \pm 49^{\mathrm{bA}}$ & $875 \pm 21^{\mathrm{cE}}$ & $1692 \pm 18^{\mathrm{cB}}$ \\
Acidified acetone extraction & $1428 \pm 16^{\mathrm{bC}}$ & $535 \pm 31^{\mathrm{cE}}$ & $6055 \pm 45^{\mathrm{aA}}$ & $729 \pm 24^{\mathrm{dD}}$ & $3104 \pm 32^{\mathrm{aB}}$ \\
\hline
\end{tabular}

Different superscript lower-case letters in each column show significant difference at $P<0.05$. Different superscript capital letters in each row show significant difference at $P<0.05$ 

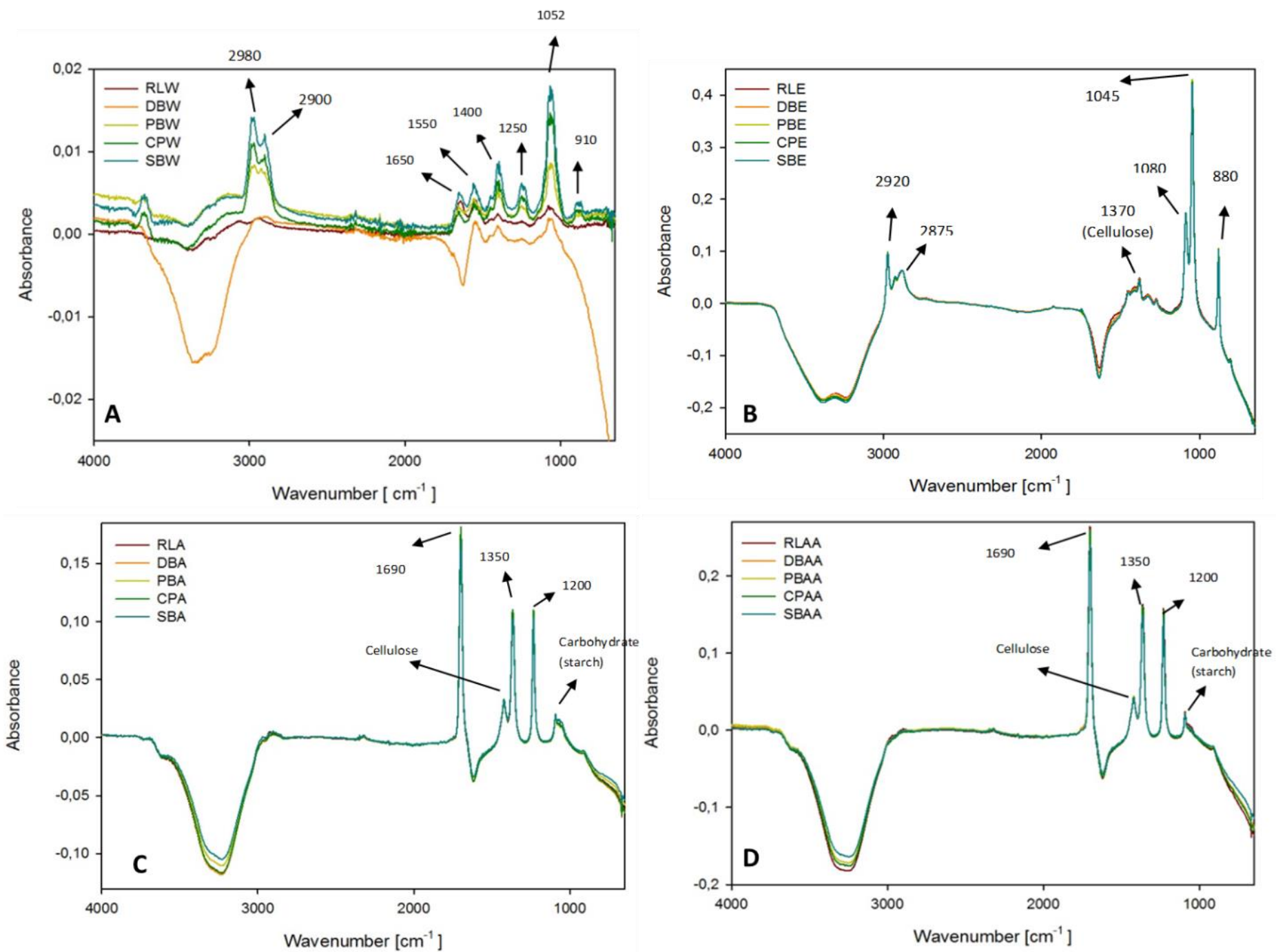

Figure 1. FT-IR spectra of legumes extracted with A) water (W) B) ethanol (E) C) acetone/water (50:50\%) (AW) D) acetone/water/acetic acid (70:29.5:0.5 \%) (AA). RL: Red lentil, DB: Dry (white) bean, PB: Pinto bean, CP: Chickpea, SB: Soybean. 
a)

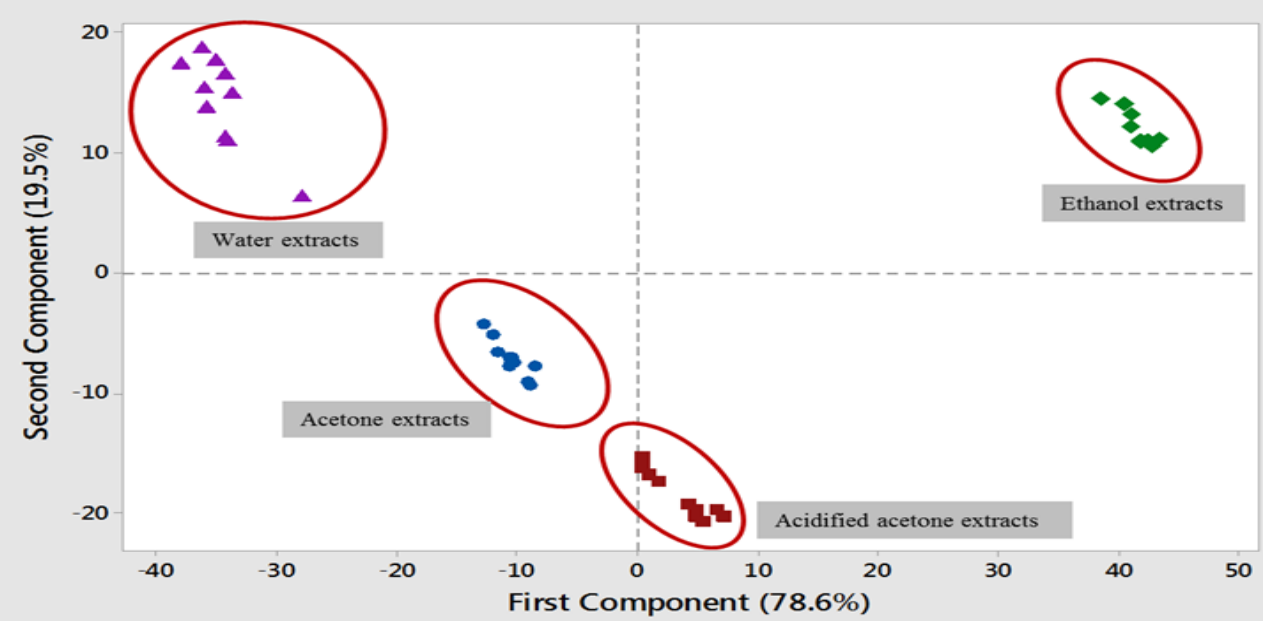

b)

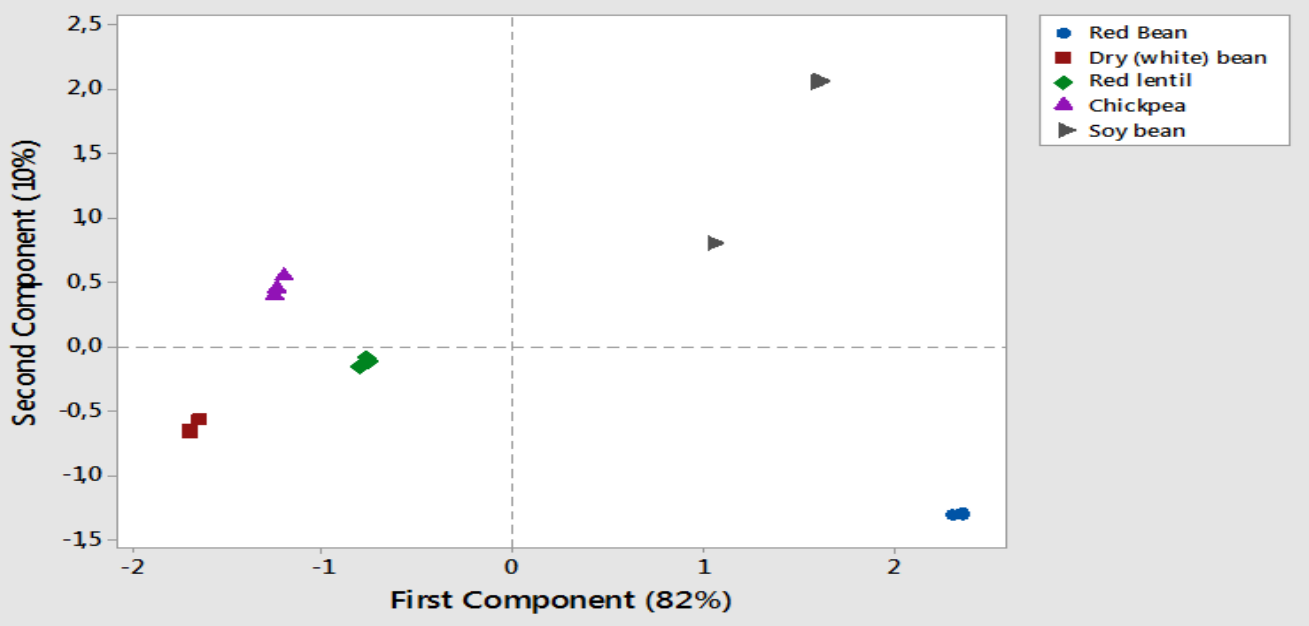

c)

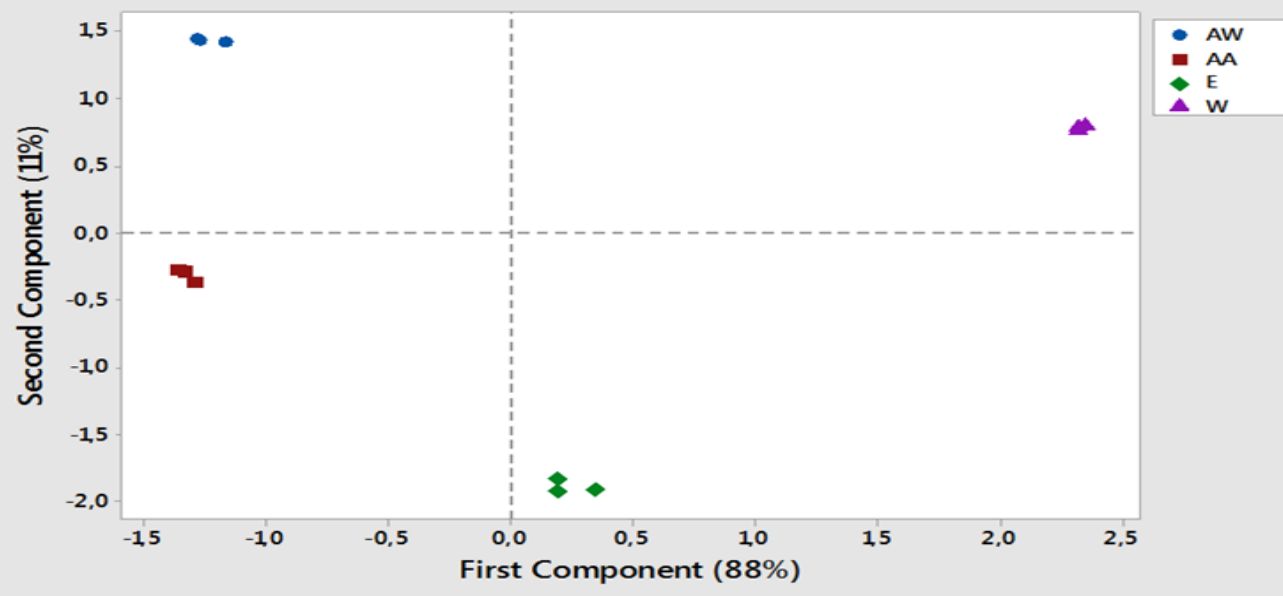

Figure 2. PCA score plot for the first two principal components of legume extracts' a) FT-IR spectra b) phenolic contents according to legume type c) phenolic contents according to solvent system 


\section{Conclusion}

In this study, the effect of solvent type on legume extracts was clearly demonstrated in a rapid way using FT-IR spectroscopic analysis in combination with chemometrics for the first time. The main functional groups were determined with FT-IR spectra of different legume extracts. Legume samples were successfully classified with PCA model constructed with two principal components according to the extraction method with different solvents. TPC analysis also showed that there were great variations in TPC of different solvent extracts in each legume based on legume type and solvent system in correlation with the FT-IR spectra of legume extracts. Moreover, the more practical comparison between the functional groups of different legumes obtained by different solvents was provided. This study revealed that FTIR could be used potentially for rapid characterization of functional groups in legume samples to generate a general perspective based on different extraction systems in relation with phenolic content analysis.

\section{Acknowledgement}

This work was partially supported by Adana Science and Technology University Scientific Research Coordination Unit. Project Number: MÜHDBF.GIDA.2015-14.

\section{References}

Bassbasi, M., De Luca, M., Ioele, G., Oussama, A. \& Ragno, G. (2014). Prediction of the geographical origin of butters by partial least square discriminant analysis (PLS-DA) applied to infrared spectroscopy (FTIR) data. Journal of Food Composition and Analysis, 33(2), 210-215.

Cai, J.X., Wang, Y. F., Xi, X. G., Li, H. \& Wei, X. L. (2015). Using FTIR spectra and pattern recognition for discrimination of tea varieties. International Journal of Biological Macromolecules, 78, 439-446.

Chung, H.-J. \& Liu, Q. (2012). Physicochemical properties and in vitro digestibility of flour and starch from pea (Pisum sativum L.) cultivars. International Journal of Biological Macromolecules, 50(1), 131-137.

Demir, P., Onde, S., Severcan, F. (2015). Phylogeny of cultivated and wild wheat species using ATR-FTIR spectroscopy. Spectrochimica Acta - Part A: Molecular and Biomolecular Spectroscopy, 135, 757-763.

Eriksson, L., Johansson, E., Kettaneh-Wold, N., Wold, S.
(2001). Multi- and mega-variate data analysis: principles and applications. Umea: Umetrics Academy, $\mathrm{p}$. 533, ISBN 9197373052

Escarpa, A., Gonzalez, M.C. (2001). Total extractable phenolic chromatographic index: an overview of the phenolic class contents from different sources of foods. European Food Research and Technology, 212, 439444.

Graham Solomon, T.W., Craig Fryhle, S.S. (2014). Families of Carbon Compounds. In Organic Chemistry (p. 8698). John Wiley \& Sons Singapore Pte. Ltd. ISBN 978975-8431-87-8

Guerrero, P., Garrido, T., Leceta, I. \& De La Caba, K. (2013). Films based on proteins and polysaccharides: Preparation and physical-chemical characterization. European Polymer Journal, 49(11), 3713-3721.

Guerrero, P., Kerry, J.P., De La Caba, K. (2014). FTIR characterization of protein-polysaccharide interactions in extruded blends. Carbohydrate Polymers, 111, 598605.

Gurdeniz, G., Ozen, B. (2009). Detection of adulteration of extra-virgin olive oil by chemometric analysis of midinfrared spectral data. Food Chemistry, 116(2), 519525.

Hu, Y., Pan, Z.J., Liao, W., Li, J., Gruget, P., Kitts, D.D., $\mathrm{Lu}, \mathrm{X}$. (2016). Determination of antioxidant capacity and phenolic content of chocolate by attenuated total reflectance-Fourier transformed - infrared spectroscopy. Food Chemistry, 202, 254-261.

Hurtado-Fernández, E., Gómez-Romero, M., CarrascoPancorbo, A., Fernández-Gutiérrez Alberto, A. (2010). Application and potential of capillary electroseparation methods to determine antioxidant phenolic compounds from plant food material. Journal of Pharmaceutical and Biomedical Analysis, 53(5), 1130-1160.

Javidnia, K., Parish, M., Karimi, S., Hemmateenejad, B. (2013). Discrimination of edible oils and fats by combination of multivariate pattern recognition and FT-IR spectroscopy: A comparative study between different modeling methods. Spectrochimica Acta Part A: Molecular and Biomolecular Spectroscopy, 104, 175-181.

Koehnlein, E.A., Koehnlein, E.M., Correa, R.C.G., Nishida, 
V.S., Correa, V.G., Bracht, A., Peralta, R.M. (2016). Analysis of a whole diet in terms of phenolic content and antioxidant capacity: effects of a simulated gastrointestinal digestion. International Journal of Food Sciences and Nutrition, 67(6), 614-623.

Li, B., Wang, H., Zhao, Q., Ouyang, J., Wu, Y. (2015). Rapid detection of authenticity and adulteration of walnut oil by FTIR and fluorescence spectroscopy: A comparative study. Food Chemistry, 181, 25-30.

Lin-Vien, D., Colthup, N.B., Fateley, W.G., Grasselli, J.G. (1991) The Handbook of Infrared and Raman Characteristic Frequencies of Organic Molecules. London: Academic Press, p. 45-60, ISBN 0124511600.

Lu, X., Wang, J., Al-Qadiri, H. M., Ross, C. F., Powers, J. R., Tang, J. \& Rasco, B. A. (2011). Determination of total phenolic content and antioxidant capacity of onion (Allium cepa) and shallot (Allium oschaninii) using infrared spectroscopy. Food Chemistry, 129(2), 637644.

Marimuthu, M., Gurumoorthi, P. (2013). Phytochemical Screening and FT-IR Studies on Wild and Common South Indian Legumes. Asian Journal of Pharmaceutical and Clinical Research, 6, 141-144.

Naumann, A., Heine, G. \& Rauber, R. (2010). Efficient discrimination of oat and pea roots by cluster analysis of Fourier transform infrared (FTIR) spectra. Field Crops Research, 119(1), 78-84.

Oomah, B.D., Caspar, F., Malcolmson, L.J., Bellido, A. S. (2011). Phenolics and antioxidant activity of lentil and pea hulls. Food Research International, 44(1), 436441.

Rohman, A., Riyanto, S., Sasi, A. M. \& Yusof, F. M. (2014). The use of FTIR spectroscopy in combination with chemometrics for the authentication of red fruit (Pandanus conoideus Lam) oil from sunflower and palm oils. Food Bioscience, 7, 64-70.
Sanati, M. \& Andersson, A. (1993). DRIFT study of the oxidation and the ammoxidation of toluene over a TiO, (B )-supported vanadia catalyst. Journal of Molecular Catalysis, 81, 51-62.

Shevkani, K., Singh, N., Kaur, A. \& Rana, J. C. (2015). Structural and functional characterization of kidney bean and field pea protein isolates: A comparative study. Food Hydrocolloids, 43, 679-689.

Silva, S. D., Feliciano, R. P., Boas, L. V. \& Bronze, M. R. (2014). Application of FTIR-ATR to Moscatel dessert wines for prediction of total phenolic and flavonoid contents and antioxidant capacity. Food Chemistry, 150, 489-493.

Singh, R. K., Kukrety, A., Sharma, O. P., Baranwal, S., Atray, N. \& Ray, S. S. (2016). Study of a novel phenolic-ester as antioxidant additive in lube, biodiesel and blended diesel. Journal of Industrial and Engineering Chemistry, 37, 27-31.

Singleton, V.L., Rossi, J.A. (1965). Colorimetry of total phenolics with phosphomolybdic-phosphotungstic acid reagents. American Journal of Enology and Viticulture, $16,144-158$.

Xu, B.J., Chang, S.K.C. (2007). A comparative study on phenolic profiles and antioxidant activities of legumes as affected by extraction solvents. Journal of Food Science, 72(2), 159-166.

Xu, L., Cai, C.B., Cui, H.F., Ye, Z.H., Yu, X.P. (2012). Rapid discrimination of pork in Halal and non-Halal Chinese ham sausages by Fourier transform infrared (FTIR) spectroscopy and chemometrics. Meat Science, 92(4), 506-510.

Zhao, Y., Du, S., Wang, H., Cai, M. (2014). In vitro antioxidant activity of extracts from common legumes. Food Chemistry, 152, 462-466. 